\title{
Cholinergic modulation of the CAN current may adjust neural dynamics for active memory maintenance, spatial navigation and time-compressed replay
}

\author{
Motoharu Yoshida ${ }^{1,2 *}$, Beate Knauer ${ }^{2}$ and Arthur Jochems ${ }^{2}$ \\ ${ }^{1}$ Faculty of Psychology, Mercator Research Group - Structure of Memory, Ruhr-University Bochum, Bochum, Germany \\ 2 International Graduate School for Neuroscience, Ruhr-University Bochum, Bochum, Germany
}

Edited by:

Yasser Roudi, Norwegian University of Science and Technology, Norway

\section{Reviewed by:}

David J. Margolis, University of

Zurich, Switzerland

Francesco P. Battaglia, Universiteit

van Amsterdam, Netherlands

Cristina Savin, Cambridge

University, UK

\section{*Correspondence:}

Motoharu Yoshida, Faculty of

Psychology, Mercator Research

Group, Ruhr-University Bochum, GA

04/49, Universitatstrasse 150, 44801

Bochum, Germany.

e-mail: motoharu.yoshida@rub.de
Suppression of cholinergic receptors and inactivation of the septum impair short-term memory, and disrupt place cell and grid cell activity in the medial temporal lobe (MTL). Location-dependent hippocampal place cell firing during active waking, when the acetylcholine level is high, switches to time-compressed replay activity during quiet waking and slow-wave-sleep (SWS), when the acetylcholine level is low. However, it remains largely unknown how acetylcholine supports short-term memory, spatial navigation, and the functional switch to replay mode in the MTL. In this paper, we focus on the role of the calcium-activated non-specific cationic (CAN) current which is activated by acetylcholine. The CAN current is known to underlie persistent firing, which could serve as a memory trace in many neurons in the MTL. Here, we review the CAN current and discuss possible roles of the CAN current in short-term memory and spatial navigation. We further propose a novel theoretical model where the CAN current switches the hippocampal place cell activity between real-time and time-compressed sequential activity during encoding and consolidation, respectively.

Keywords: spatial navigation, short-term memory, calcium-activated non-specific cationic current, acetylcholine, encoding, consolidation, medial temporal lobe, hippocampus

\section{INTRODUCTION}

It has been suggested that the medial temporal lobe (MTL) supports memory formation through two distinct processes: encoding and consolidation (Buzsáki, 1989; McClelland et al., 1995; reviewed by McGaugh, 2000). Since the discovery of timecompressed "replay" of place cell activity during slow-wave-sleep (SWS) and the quiet waking state (Wilson and McNaughton, 1994; Lee and Wilson, 2002; Foster and Wilson, 2006), modeling studies have proposed that activity of place cells during active waking supports encoding, and time-compressed replay supports consolidation (Jensen and Lisman, 1996; Shen and McNaughton, 1996; Molter et al., 2007). In the encoding mode, hippocampal place cells fire sequentially with temporal overlap with adjacent place cells, depending on the location of the animal. This is believed to induce synaptic modifications which will, in the subsequent consolidation mode, activate the same set of place cells in the same sequence but with a highly ( $\sim 20$ times) compressed time scale (Lee and Wilson, 2002).

The cholinergic system is believed to modulate the dynamics of the MTL between active waking, quiet waking, and SWS modes in the hippocampus, making the information flow suitable for encoding and consolidation (Hasselmo, 1999). This theory is based on the fact that the acetylcholine level is high during active waking, and lower during quiet waking and SWS (Kametani and Kawamura, 1990; Marrosu et al., 1995). Indeed, inactivation of the medial septum, which gives rise to major cholinergic projection to the MTL, reduces the activity and location-specificity of place cells and grid cells (Mizumori et al., 1989; Brandon et al., 2011; Koenig et al., 2011). In addition, infusion of a cholinergic receptor antagonist reduces the activity and location-specificity of hippocampal place cells (Brazhnik et al., 2003). This later study also shows that the cholinergic receptor antagonist reduced the theta activity period, which corresponds to active waking, and increased the large-amplitude irregular activity (ripple activity) period and the out-of-field firing, which corresponds to quiet waking. These observations suggest that cholinergic activation is crucial for physiological activity of the MTL spatial cells during active waking, and suppression of cholinergic activation contributes to switching the dynamical activities of place cells to replay mode. However, the underlying cellular mechanisms for the switch of dynamics by acetylcholine in the MTL are largely unknown.

Prior modeling studies on encoding and consolidation used sensory input to switch the time-scale of sequential activity between real-time and time-compressed activity (Jensen and Lisman, 1996; Molter et al., 2007). In Hasselmo (1999), synaptic suppression due to a high acetylcholine level was proposed to explain the encoding and consolidation functions. However, focus was not on the modulation of intrinsic dynamics. In this paper, we focus on how acetylcholine enables the network dynamics to switch within the MTL independently of the sensory input. We focus on the role of the calcium-activated non-specific cationic (CAN) membrane current which is found in the key areas for spatial navigation, such as the postsubiculum, the medial 
entorhinal cortex (MEC) and the hippocampus (Gähwiler and Dreifuss, 1982; Benardo and Prince, 1982b; Caeser et al., 1993; Fraser and MacVicar, 1996; Klink and Alonso, 1997; Magistretti et al., 2004; Yoshida and Hasselmo, 2009a,b). The CAN current is activated through cholinergic receptor activation and through calcium entry to individual neurons, and it greatly excites the membrane, often depolarizing the membrane potential above the firing threshold.

In this paper, we (1) review the effect of the cholinergic modulation on single cells and synaptic transmission, focusing on the modulation by the CAN current. In short, CAN current enables single neurons to maintain information from the past through persistent firing, which is a repetitive neural spiking activity that outlasts triggering stimulation, (2) discuss the possible role of the CAN current in MTL-dependent short-term memory tasks, (3) discuss the possible role of the CAN current in spatial navigation, (4) propose a theoretical model of how the CAN current could support switching from time-compressed fast replay/preplay mode to slower real-time firing mode during active waking, and (5) discuss how the CAN current might be used to intentionally slow the network activity during encoding, to allow the network to perform future planning or sequential episodic memory recall in a speed faster than real-time. Furthermore, we discuss how our model could account for firing dynamics of "time cell” (MacDonald et al., 2011).

\section{EFFECTS OF ACETYLCHOLINE ON NEURONAL PROPERTIES: IN VITRO STUDIES ACTIVATION OF CAN CURRENT THROUGH CHOLINERGIC RECEPTOR}

Application of acetylcholine or cholinergic receptor agonist mediates slow membrane potential depolarization, increased excitability and reduced firing frequency adaptation (Segal, 1982; Benardo and Prince, 1982a; Cole and Nicoll, 1983; Storm, 1989). This is partly due to the suppression of potassium currents such as the M-current and the calcium-activated potassium current (Halliwell and Adams, 1982; Cole and Nicoll, 1983; Madison et al., 1987). However, this slow depolarization was not fully blocked under the suppression of potassium channels and activation of calcium-activated non-specific cationic current (CAN current) was found to underlie this slow depolarization in the hippocampal pyramidal cells (Gähwiler and Dreifuss, 1982; Benardo and Prince, 1982b; Caeser et al., 1993; Fraser and MacVicar, 1996) and cortical pyramidal cells (Andrade, 1991). Because of the calcium dependency of the CAN current, a calcium channel blockade suppresses the depolarization (Fraser and MacVicar, 1996). On the other hand, spiking or depolarization of the membrane potential that increases calcium influx causes further activation of the CAN current under constant cholinergic activation (Caeser et al., 1993; Fraser and MacVicar, 1996; Kawasaki et al., 1999). In these studies, a brief current injection to the cell drove subthreshold or suprathreshold depolarization due to the CAN current for up to several seconds after the offset of the current injection. This depolarization triggered by a brief stimulation is called a "plateau potential." Persistent firing is often caused by the plateau potential which is large enough to depolarize the membrane potential above the spike threshold.

\section{CAN CURRENT DRIVEN PERSISTENT FIRING}

Subsequent to the above-mentioned studies, the role of the CAN current in persistent firing was studied extensively in various MTL areas (reviewed in Major and Tank, 2004; Reboreda et al., 2011). The significance of the persistent firing found in the MTL areas was that firing often persisted for more than a few minutes without decreasing its firing frequency. Figure 1 shows examples of persistent firing recorded in vitro from neurons in the postsubiculum (Yoshida and Hasselmo, 2009a) where head direction cells have been found in vivo (Ranck, 1984; Taube et al., 1990a,b). These recordings were done in an acute brain slice preparation using the cholinergic receptor agonist carbachol $(10 \mu \mathrm{M})$. First, in a control condition without carbachol, a brief current injection ( $2 \mathrm{~s}$ ) induced spiking of the neuron during the stimulation, but the neuron remained quiet once the stimulation was terminated (Figure 1A). In contrast, in the presence of carbachol, spikes induced by the same brief current stimulation drove stable persistent firing at a frequency of about $3-10 \mathrm{~Hz}$ (Figure 1B). In many cells, persistent firing continued for more than a few minutes, at which point persistent firing was terminated by the experimenter using a hyperpolarizing current injection. In this paper, we call this type of persistent firing "long-lasting persistent firing." In other neurons, persistent firing ended within $30 \mathrm{~s}$ (Figure 1C). We call this type of persistent firing "self-terminating persistent firing." Stable long-lasting persistent firing in vitro was found in layer II (Yoshida and Hasselmo, 2009b), in layer V (Egorov et al., 2002; Reboreda et al., 2007) neurons in the MEC, and in layer III neurons in the lateral entorhinal cortex (LEC; Tahvildari et al., 2007). Similar persistent firing has recently been shown in the perirhinal cortex (Navaroli et al., 2011). In addition, our preliminary observation shows long-lasting persistent firing in hippocampal CA1 and CA3 pyramidal cells in rats (unpublished observation by Beate Knauer and Arthur Jochems).

There is debate as to whether or not synaptic transmission is necessary for persistent firing (Major and Tank, 2004). For example, persistent firing observed as an "UP" state in a slice model of cortical SWS oscillation is dependent on intact AMPA and NMDA synaptic transmission (Shu et al., 2003). On the other hand, evidence suggests that persistent firing observed in brain slices from many of the MTL areas is driven by mechanisms intrinsic to individual neurons. Persistent firing can be observed in the presence of ionotoropic glutamatergic and $\mathrm{GABA}_{\mathrm{A}}$ synaptic blockers in the entorhinal cortex, postsubiculum, and perirhinal cortex (Figure 2A; Egorov et al., 2002; Yoshida and Hasselmo, 2009a; Navaroli et al., 2011). In addition, persistent firing is blocked in the absence of calcium (Figure 2B) or by the CAN current blocker flufenamic acid in these three areas (Figure 2C; Egorov et al., 2002; Tahvildari et al., 2008; Yoshida and Hasselmo, 2009a; Zhang et al., 2011; Navaroli et al., 2011). Furthermore, activation of muscarinic receptors (Egorov et al., 2002; Navaroli et al., 2011) and phospholipase C $\beta$ (PLC $\beta$; Zhang et al., 2011), which leads to CAN current activation, are shown to be necessary for the induction of persistent firing. As for the molecular correlates of the CAN current, it has been shown that transient receptor potential cation (TRPC) channels underlie the CAN current (Tai et al., 2010; Zhang et al., 2011; reviewed by Reboreda et al., 2011). These observations strongly suggest that 

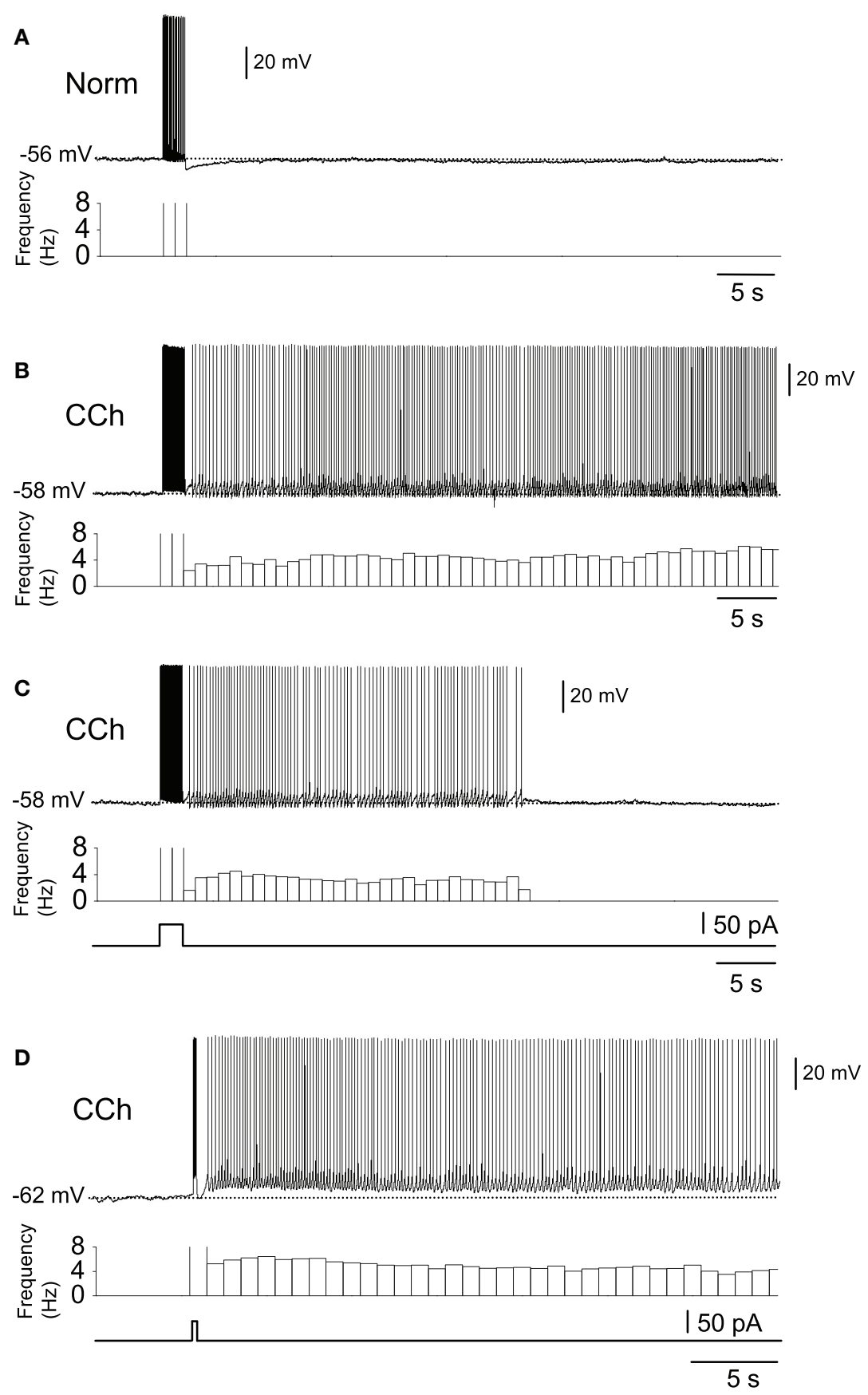

FIGURE 1 | In vitro recordings of persistent firing in the rat postsubiculum. (A) In the normal ACSF without the cholinergic receptor agonist carbachol, a brief current injection ( $2 \mathrm{~s}, 50 \mathrm{pA}$ ) elicited action potentials only during stimulation. (B) Long-lasting persistent firing. In the presence of carbachol $(10 \mu \mathrm{M})$, the same current injection caused stable sustained firing lasting several minutes. (C) Self-terminating persistent firing. Under the same conditions as in (B), some cells showed persistent firing that lasted for less than $30 \mathrm{~s}$. (D) Persistent firing induced by shorter stimulation. In the postsubiculum, $200 \mathrm{~ms}$ of stimulation was often enough to elicit long-lasting persistent firing. Norm, Normal ACSF; Cch, carbachol. Modified from Yoshida and Hasselmo (2009a). many MTL neurons can exhibit persistent firing through intrinsic cellular mechanisms. In an in vivo condition, both this intrinsic mechanism and the synaptic mechanism may contribute to persistent firing.

\section{MORE PHYSIOLOGICAL INDUCTION OF PERSISTENT FIRING}

Several studies have tested detailed properties of persistent firing in the MTL to estimate its contribution to the function of the MTL. As described in detail in "Possible Roles of CAN Current 


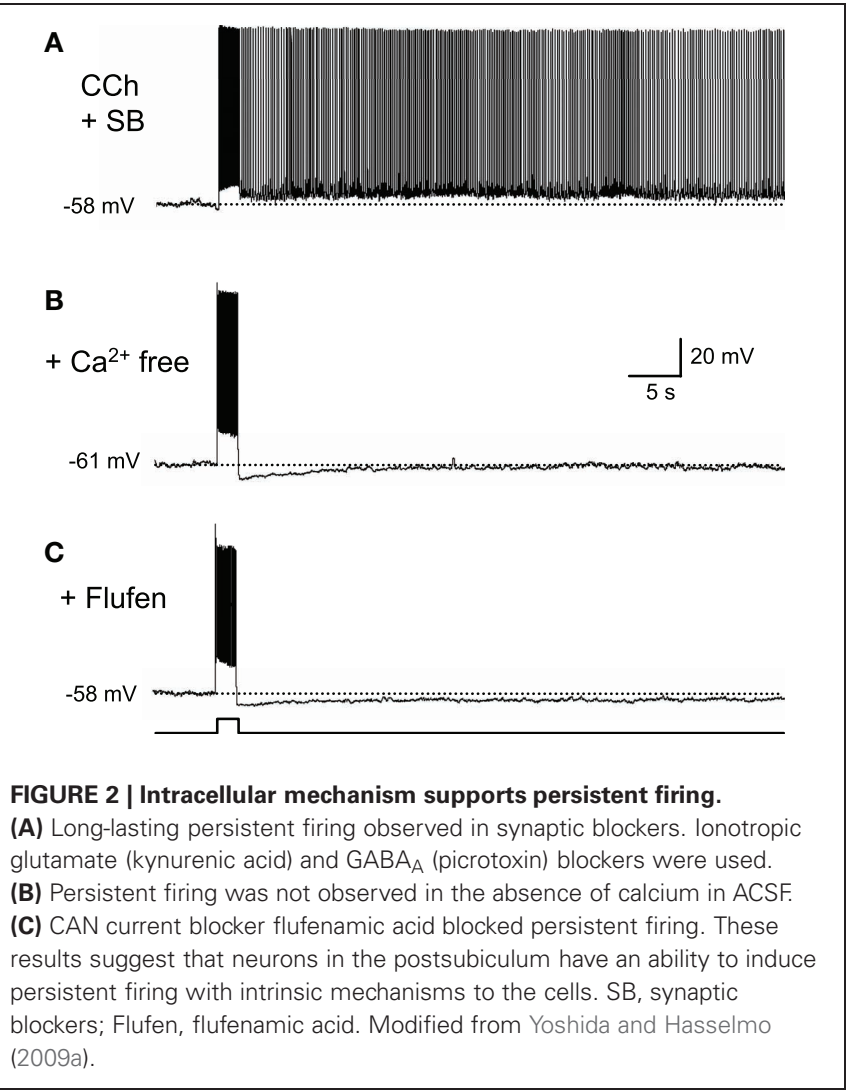

in Active Maintenance of Memory in MTL," the MTL areas are important for trace conditioning tasks (Kim et al., 1995; Weiss et al., 1999; McEchron et al., 2000; Tseng et al., 2004; KholodarSmith et al., 2008; Esclassan et al., 2009) where an animal needs to associate two stimuli which are separated by a trace period (a few hundred milliseconds to tens of seconds). For the animal to acquire this task, information from the first stimulus (conditioned stimulus; CS) has to be maintained during the trace period until the second stimulus (unconditioned stimulus; US) is delivered. In vivo single unit recordings show persistent firing in a sub-population of hippocampal CA1 neurons during the trace period (Solomon et al., 1986; McEchron et al., 2001, 2003) and the intrinsic persistent firing supported by the CAN current has been suggested to underlie this in vivo persistent firing (Fransén et al., 2002).

Since the duration of the CS is only a few hundreds of milliseconds in some trace conditioning tasks, an induction of persistent firing by a stimulation with comparable duration was tested. It has been shown that in the entorhinal cortex and in the postsubiculum, a current pulse, as short as 300 and $200 \mathrm{~ms}$, respectively, is sufficient to induce persistent firing (Egorov et al., 2002; Yoshida and Hasselmo, 2009a). In the case of the postsubiculum, a $200 \mathrm{~ms}$ current injection, which elicited only several spikes, drove persistent firing in more than $60 \%$ of cells (Figure 1D; Yoshida and Hasselmo, 2009a), suggesting that a physiological level of excitation is sufficient to induce persistent firing.

Persistent firing can also be initiated using synaptic stimulation instead of current injection in the entorhinal cortex (Egorov et al., 2002; Tahvildari et al., 2007; Yoshida et al., 2008). In addition, it has been suggested that an endogenous level of acetylcholine is sufficient for the induction of persistent firing in the amygdala (Egorov et al., 2006). In this study, cholinergic afferent fibers were stimulated instead of applying a cholinergic agonist to the brain slice preparation. Stimulation of the cholinergic afferent and subsequent brief current injection triggered persistent firing in principal neurons in the amygdala.

Persistent firing observed in vivo is typically terminated as the US is delivered. In in vitro studies, it has been shown that persistent firing can be terminated through hyperpolarization by current injection in layer $\mathrm{V}$ cells in the MEC and in cells in the perirhinal cortex (Egorov et al., 2002; Reboreda et al., 2007; Navaroli et al., 2011), suggesting that inhibitory synaptic input could be used to terminate persistent firing. Interestingly, in layer III of the LEC, persistent firing can be terminated by an application of a second positive current injection or synaptic stimulation (Figure 4B; Tahvildari et al., 2007) suggesting that different areas in the MTL might employ different means to terminate persistent firing.

An additional interesting feature of intrinsic persistent firing is the "integration" mechanism. In cells in the MEC layer V, perirhinal cortex and amygdala (Egorov et al., 2002, 2006; Navaroli et al., 2011), repeatedly applied current pulse stimulation increased the frequency of persistent firing in a step-like manner after each stimulation. Therefore, past sequences of stimulation in individual cells could be "integrated" into the current frequency of the persistent firing.

\section{LONG-LASTING PERSISTENT FIRING IN THE HIPPOCAMPUS}

Although many earlier studies of the CAN current were performed in hippocampal pyramidal cells, there has been no clear evidence for long-lasting persistent firing in this type of cell. Fraser and MacVicar (1996) reported short-lasting plateau potential in CA1 pyramidal cells using relatively high $(20 \mu \mathrm{M})$ concentration of carbachol and current injection. In this study, pyramidal cells typically showed strong depolarization beyond the spike threshold where action potentials were not repeatedly elicited, as a response to the current injection ( $800 \mathrm{~ms}$ ). After the current injection, this plateau potential typically lasted for only several seconds before the membrane potential went back to the pre-stimulus level. In our laboratory we tested whether stable, long-lasting persistent firing could be elicited in hippocampal CA1 and CA3 pyramidal cells in vitro. In the presence of a lower concentration of carbachol $(10 \mu \mathrm{M})$, a subset of CA1 and CA3 pyramidal neurons showed long-lasting persistent firing, up to a few minutes, similar to the persistent firing in the MEC (unpublished observation by Beate Knauer and Arthur Jochems).

Recently, long-lasting persistent firing has been found in hippocampal inhibitory interneurons (Sheffield et al., 2011). The mechanism for the induction of this persistent firing in interneurons seems to be very different from those in principal neurons. Persistent firing in interneurons does not require cholinergic receptor activation or calcium, indicating that the CAN current is not involved. However, this type of persistent firing requires intact gap junctions. In addition, induction of persistent firing requires repetitive stimulation for tens of seconds to minutes, suggesting 


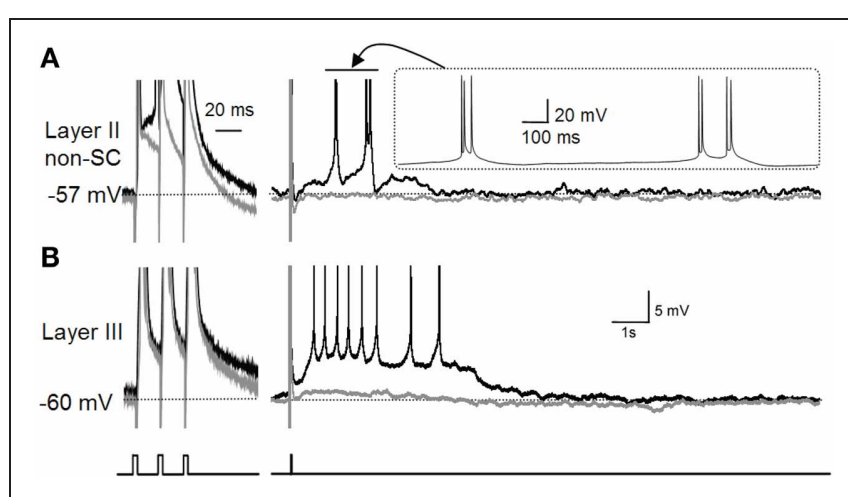

FIGURE 3 | Effect of M-current suppression on persistent firing. (A) The effect of the M-current in layer II non-stellate cells in the MEC. (B) The effect of the M-current in layer III pyramidal cells in the MEC. Suppression of the M-current by linopirdine revealed a plateau potential after three induced spikes in both types of neurons with different firing properties. Layer II non-stellate cells fired in a high-frequency burst while layer III cells fired regularly during plateau potential. Gray traces are control recordings and black traces are recordings in linopirdine. non-SC, non-stellate cell. Figures were modified from Yoshida and Alonso (2007).

that persistent firing in interneurons could be more suitable for excitability control than short-term maintenance of information.

\section{MODULATION OF OTHER NEURAL PROPERTIES BY ACETYLCHOLINE}

It is worth noting that the effect of acetylcholine is not limited to the modulation of the CAN current. As briefly mentioned above, acetylcholine suppresses the $\mathrm{M}$-current and the calcium-activated potassium current (Reviewed by Giocomo and Hasselmo, 2007). Suppression of the potassium currents may enhance the depolarization of the membrane potential by the CAN current. In fact, in the entorhinal cortex, suppression of the M-current revealed a plateau potential and self-terminating persistent firing (Figure 3; Yoshida and Alonso, 2007). This persistent firing was probably due to an endogenously active CAN current which was not visible in the presence of the M-current as the M-current was masking this inward current.

An additional well-established effect of cholinergic activation is the modulation of synaptic properties (Hasselmo, 1999; Giocomo and Hasselmo, 2007). First, synaptic plasticity is enhanced under cholinergic stimulation (Sugisaki et al., 2011). Second, synaptic conductance is suppressed in a systematic manner by acetylcholine (Hasselmo, 1999; Giocomo and Hasselmo, 2007). Interestingly, acetylcholine suppresses intrinsic synaptic transmission more strongly than afferent synapses. For example, excitatory synaptic connections within the hippocampus, such as the Schaffer collateral and CA3 recurrent connections, are strongly suppressed by cholinergic activation (Hasselmo and Schnell, 1994; Kremin and Hasselmo, 2007).

\section{POSSIBLE ROLES OF CAN CURRENT IN ACTIVE MAINTENANCE OF MEMORY IN MTL MTL SUPPORTS ACTIVE MAINTENANCE OF MEMORY}

The MTL has long been known for its role in long-term memory (Squire, 1992). However, there are also many recent reports that support a role of the MTL in short-term memory retention, where the duration ranged from a few seconds to tens of seconds (Hannula et al., 2006; Olson et al., 2006; Hartley et al., 2007; Cashdollar et al., 2009). Some authors have suggested that such short-term retention might bridge the gap between two temporally separated events to form sequential memory (Wallenstein et al., 1998; Naya and Suzuki, 2011).

Although evidence for the involvement of the MTL in shortterm memory in humans is relatively new, animal studies have long been suggesting its role in short-term memory retention. Strong evidence for this comes from the trace conditioning paradigm which is a subtype of classical conditioning. In this task, animals need to maintain the information about the CS until the US arrives in order to learn the association between the CS and the US. Animals with a lesion to the hippocampus, entorhinal cortex, or perirhinal cortex are impaired in this type of task (Kim et al., 1995; Weiss et al., 1999; McEchron et al., 2000; Tseng et al., 2004; Kholodar-Smith et al., 2008; Esclassan et al., 2009). More importantly, lesioned animals can learn the same conditioning task if the trace period is removed (delay task where CS and US were continuous in time; Kim et al., 1995; Weiss et al., 1999; McEchron et al., 2000; Tseng et al., 2004; Bangasser et al., 2006; Kholodar-Smith et al., 2008; Bang and Brown, 2009; Esclassan et al., 2009). These studies indicate that the MTL is necessary, particularly when a temporal gap exists between two stimuli (e.g., trace paradigm).

As with the trace conditioning task, the MTL, including the hippocampus and the entorhinal and perirhinal cortices, is crucial in delayed non-match to sample (DNMS) tasks in both non-human primates (Squire and Zola-Morgan, 1991) and rats (Otto and Eichenbaum, 1992a,b). The DNMS task is similar to the trace conditioning task in that the animal needs to maintain information of the first stimulus until the second stimulus arrives.

Involvement of the MTL in short-term memory retention can also be found in other experimental paradigms. In a spatial alternation task where rats were required to continuously turn right and left alternately in a T-shaped maze, both rats with and without hippocampal lesion performed well (Wood et al., 2000; Ainge et al., 2007). However, when a delay period of 2 or $10 \mathrm{~s}$ was introduced, during which the rats needed to wait before turning, this task required intact hippocampus (Ainge et al., 2007). Consistent with this, object-odor association task with temporal gap (10 s; Kesner et al., 2005), temporal sequence task (Gilbert et al., 2001), spatial choice task with 10 s of delay for rewards (Mikulka and Freeman, 1975; Rawlins et al., 1985), nonspatial sequence learning with $3 \mathrm{~s}$ and $10 \mathrm{~s}$ delay (Farovik et al., 2009), are all shown to be hippocampal-dependent. Many of these tasks become hippocampal-independent when the delay period is removed (Mikulka and Freeman, 1975; Rawlins et al., 1985; Gilbert and Kesner, 2002; Ainge et al., 2007). In summary, the MTL areas are crucial for tasks that require short-term memory.

\section{CHOLINERGIC DEPENDENCE OF SHORT-TERM MEMORY TASKS}

Suppression of cholinergic transmission in the dorsal hippocampus and entorhinal cortex impairs trace conditioning task performance in rats, while the same task without trace period is not impaired (McGaughy et al., 2005; Bang and Brown, 2009; 
Pang et al., 2010). Administration of a cholinergic antagonist impairs delayed-matching-to-sample task performance in monkeys (Penetar and McDonough, 1983). Moreover, Anagnostaras et al. (2003) have shown that M1 muscarinic cholinergic receptor $\mathrm{KO}$ mice are impaired in a working memory task with a delay period, but not in spatial learning which did not involve delay. In addition, a cholinergic blockade was found not only to impair the acquisition of these tasks, but also to reduce hippocampal activity during trace periods in humans (Schon et al., 2005). Finally, in rats, memory performance on a delay task was disrupted by lesion to the septum, which provides cholinergic afferent fiber to the MTL (Rawlins et al., 1985). These results suggest an important role of the cholinergic system in short-term memory retention.

\section{PERSISTENT FIRING MAY CONTRIBUTE TO SHORT-TERM MEMORY}

Sustained increased activity in MTL areas has been observed in the trace period of trace conditioning tasks, or during the delay period of DNMS tasks, using in vivo electrophysiological recordings in animals, and using fMRI in humans. For example, hippocampal CA1 pyramidal cells show persistent firing over $30 \mathrm{~s}$ during the delay period in a DNMS task in monkeys and rats (Figure 4A; Colombo and Gross, 1994; Hampson et al., 2004; Deadwyler and Hampson, 2004). In addition, a similar increase in the firing rate during the delay period has been observed in the entorhinal cortex in rats and monkeys in a similar task (Suzuki et al., 1997; Young et al., 1997).

Similarly, increased firing frequency has been shown during the trace period of the trace conditioning paradigm in the hippocampus in rabbits (Solomon et al., 1986; McEchron et al., 2001, 2003). Interestingly, these studies have also shown that the number of cells that responded to the delay period decreased as the animals' performance improved, while the number of cells that responded to CS and US did not change (Solomon et al., 1986; McEchron et al., 2001). This suggests that the delay period activity, but not CS or US activity, may contribute to task performance improvement. Moreover, aged animals that were impaired in acquiring this trace conditioning task, showed significantly fewer cells responding during the delay period (McEchron et al., 2001). These results suggest that sustained firing activity of the hippocampal neurons is necessary for acquiring this type of task.

Finally, in humans, fMRI imaging studies showed increased neuronal activity during the delay period (Schon et al., 2004; Olsen et al., 2009), despite relatively poor temporal and spatial resolution compared to in vivo electrophysiological recordings. In a human MEG study, it has been suggested that the hippocampus plays a pivotal role in synchronizing multiple brain areas at theta frequency during the delay phase of delayed-matchto-sample (DMS) tasks (Cashdollar et al., 2009). In summary, persistent activity observed in the MTL seems to be important for short-term memory tasks.

\section{COMPUTATIONAL MODELS OF ACTIVE MAINTENANCE BY THE CAN CURRENT}

Using computational simulation of a network of neurons with the CAN current, Fransén et al. (2002) have shown that the CAN current may allow sustained spiking in the entorhinal cortex which was robust to noise. Another line of research asked how multiple stimuli, that are presented sequentially one after another, can be stored as short-term memory without losing the sequence in which the stimuli were presented (Lisman and Idiart, 1995; Jensen and Lisman, 1996; Koene and Hasselmo, 2008). In these models, each memory trace was stored by one neuron that showed persistent firing in a theta frequency $(4-14 \mathrm{~Hz})$ due to the CAN current kinetics. Although each cell showed persistent firing at the same frequency, these neurons fired at slightly different timings from each other with a specific delay, which was equal to one gamma cycle $(\sim 40 \mathrm{~Hz}$; Lisman and Idiart, 1995; Jensen and Lisman, 1996). Koene and Hasselmo (2008) further suggested that memory items in the nested theta and gamma model can

\section{A$$
\text { Persistent firing in the }
$$ monkey hippocampus}

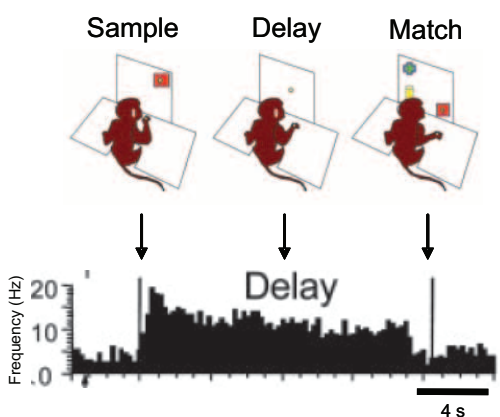

FIGURE 4 | Persistent firing as the mechanism for short-term memory function of the MTL. (A) Persistent firing recorded in monkey hippocampus during a delayed match-to-sample task. Some neurons in the hippocampus continued firing throughout the delay period, when the monkey needed to retain a piece of information presented at the sample phase. (B) In the brain slice preparation of lateral entorhinal cortex, brief (4s) stimulation can trigger

\section{B Persistent firing in the brain slice of rat lateral entorhinal cortex}

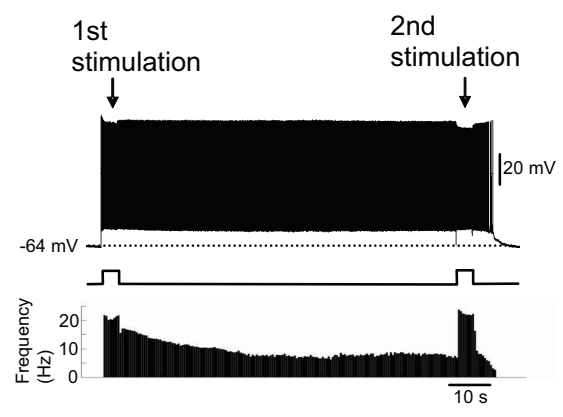

persistent firing supported by the CAN current. This persistent firing could be terminated by a second brief stimulation. Note the very similar time course of spike frequencies in in vivo and in vitro recordings. Single cell level persistent firing in the MTL could support short-term memory tasks. Figure in (A): modified from Hampson et al. (2004). Figure in (B): Tahvildari et al. (2007). Figure was re-drawn from original recording. 
be updated with physiological mechanisms upon arrival of a new stimulation. In this model, CAN current activity set the persistent firing in the theta frequency range, and the gamma rhythm was set by an interneuron network. In these computational models, the persistent firing driven by the CAN current played an important role in short-term memory retention. These computational studies, therefore, support the idea that the CAN current driven persistent firing could support short-term memory function in the MTL.

\section{POSSIBLE ROLES OF CAN CURRENT IN SPATIAL NAVIGATION}

In this section, we first introduce evidence that suggests requirement of short-term memory for spatial navigation. Second, we describe previously proposed and possible roles of CAN currentdriven persistent firing in spatial navigation.

\section{SPATIAL NAVIGATION AND SHORT-TERM MEMORY}

Since the discovery of place cells whose activity corresponds to the location of an animal (O'Keefe and Dostrovsky, 1971), studies in this field have revealed a vast amount of knowledge as to how spatial information is represented in the MTL (See Moser et al., 2008 for review). One may see the activity of head direction cells, grid cells, or place cells as a representation that is simply the sum of incoming sensory inputs. However, evidence suggests that this is not the case.

In daily life, we may need to walk into an underground subway station with very limited spatial cues, go through staircases with turns, come out through another exit and then resume walking in the direction in which we were originally going. To do this successfully, we need to maintain a sense of direction, even when we cannot see landmarks outside the station that could guide us. This issue has been explored in animal studies. Head direction cells in the postsubiculum in rats (Ranck, 1984; Taube et al., 1990a,b; Sharp, 1996; Boccara et al., 2010) continuously fire as long as the animal's head is pointed in the preferred direction of the cell. More importantly, they do not stop firing, even in total darkness, as long as the direction of the head points toward the preferred direction of the cell, although the direction tuning of the head direction cells gradually diverges from the original (Taube et al., 1990b; Goodridge et al., 1998). Therefore, the head direction system must have a means to actively maintain its firing to form an internal representation. This internal representation is thought to be updated by occasional self-motion cues such as angular velocity signals when spatial cues are absent (McNaughton et al., 1991; Skaggs et al., 1995; Redish et al., 1996; Goodridge and Touretzky, 2000; Boucheny et al., 2005; Song and Wang, 2005).

Similarly to the head direction cells, grid cells in the MEC, and place cells in the hippocampus, do not disappear in darkness for a certain duration (Quirk et al., 1990; Hafting et al., 2005; McNaughton et al., 2006). This suggests that animals can update their internal representation by self-motion cues. This ability is called path integration (McNaughton et al., 1991, 2006). Firing of grid cells and place cells cannot be explained solely by visual information, even under normal light conditions. Many grid cells in MEC layer II, and place cells in the hippocampus, are not sensitive to the current head direction of the animal (Muller et al., 1994;
Sargolini et al., 2006). Since the animal's visual sensory inputs will differ, according to the head direction, even at the same location, firing of these cells cannot be a simple sum of sensory inputs. Rather, spatial representation seems to involve the integration of different types of sensory information, from the past and present, which leads to an allocentric representation of the space. In this sense, spatial representation is also based on short-term memory function (Bird and Burgess, 2008).

\section{POSSIBLE CONTRIBUTION OF CAN CURRENT IN COMPUTATIONAL MODELS OF SPATIAL REPRESENTATION}

There are two distinct computational models of spatial representation: the oscillatory-interference model and the attractornetwork model (reviewed by Giocomo et al., 2011). The oscillatory-interference model of place cells and grid cells uses multiple oscillators, with slightly different frequency within a theta frequency range, impinging on to a single neuron to give rise to a spatial representation (O'Keefe and Recce, 1993; O'Keefe and Burgess, 2005). When the oscillators are in phase, this neuron fires action potentials. When oscillators are not in phase, inputs from these oscillators will be subthreshold, and do not lead to action potentials. Spatial information in this model is, therefore, maintained in phases of these independent oscillators. As for the physiological correlates of the oscillators in this model, subthreshold membrane potential oscillations (SMPOs) or persistent firing has been shown to work in computational models (Hasselmo, 2007; Hasselmo et al., 2010). In the case of persistent firing, oscillatory frequency is defined as the frequency of persistent firing, driven by the CAN current. Oscillatory-interference models with SMPOs can replicate the increasing grid spacing along the dorso-ventral axis of the MEC found in vivo (Hafting et al., 2005), if the SMPO frequency gradient along the dorsoventral axis found in in vitro intracellular recordings (Giocomo et al., 2007; Garden et al., 2008; Yoshida et al., 2011) is taken into account. On the other hand, the oscillatory-interference model is sensitive to disturbance, because a slight change in the phase of any of the oscillators affects spatial representation (Zilli et al., 2009). This sensitivity to noise, however, could be dramatically reduced if the oscillators are coupled by a synaptic network (Zilli and Hasselmo, 2010).

In contrast, the continuous attractor model does not require oscillators. Conceptually, activity of sub-population of cells in the network is a stable state in continuous attractor models. One way to implement this is to assume that neurons located close to each other in a network are connected with recurrent excitatory synapses, and that all cells receive global inhibition (e.g., Tsodyks and Sejnowski, 1995). This means that once a group of neurons starts firing, this firing can be maintained as a "bump" of activity, because the excitatory recurrent connections will keep this group of cells active, while inhibitory connections will keep the other neurons silent. The bump of activity is, therefore, a type of persistent firing supported by synaptic transmission, which will actively maintain the current location of the animal in the absence of sensory inputs in this model.

The head direction system in the postsubiculum is often modeled as a one dimensional attractor-network with excitatory synaptic connections among nearby head direction cells 
(Skaggs et al., 1995; Redish et al., 1996; Zhang, 1996; Goodridge and Touretzky, 2000). However, based on the lack of strong support for excitatory connections, models with inhibitory connections alone have been proposed (Rubin et al., 2001; Boucheny et al., 2005; Song and Wang, 2005). These recent models assumed external excitatory inputs to ensure persistent firing of head direction cells. However, the origin of the spontaneous firing or the external inputs used in these models is unclear. Similarly to the head direction system in the postsubiculum, evidence for strong recurrent excitatory synaptic connections is lacking in the MEC layer II network, where grid cells were originally discovered, and in the hippocampal CA1 region, where place cells were originally discovered.

As described above, it has recently been shown that neurons in the postsubiculum have an ability to show persistent firing through the activation of the CAN current, independently from the synaptic connections (Figures $\mathbf{1}$ and 2; Yoshida and Hasselmo, 2009a). This mechanism could be used in the models of the head direction system with inhibitory synaptic connections alone (Rubin et al., 2001; Boucheny et al., 2005; Song and Wang, 2005). In addition, MEC layer II cells (Yoshida and Hasselmo, 2009b) and hippocampal CA1 cells (unpublished observation by Beate Knauer) both have the CAN current driven persistent firing. Therefore, the intrinsic persistent firing through the CAN current could be an ideal mechanism for the attractor model to work when recurrent excitation is limited.

\section{SWITCHING BETWEEN REAL-TIME AND TIME-COMPRESSED SEOUENTIAL ACTIVITY BY THE CAN CURRENT: A THEORETICAL MODEL}

In this section, we first review evidence for the cholinergic system to switch brain states, and describe the firing pattern of hippocampal place cells in different brain states. We then propose a new model where the CAN current is used to switch the sequential firing speed from fast (time-compressed) to slow (realtime), upon activation. Finally, we discuss our model and our interpretation of the model.

\section{EVIDENCE THAT SUPPORTS SWITCHING OF INTERNAL DYNAMICS}

The acetylcholine level is high during active waking and low during SWS in the rat hippocampus and in the cat cortex (Kametani and Kawamura, 1990; Marrosu et al., 1995). The level of acetylcholine is even higher during sustained attentional tasks (Himmelheber et al., 2001; Arnold et al., 2002) and lower during quiet waking (Kametani and Kawamura, 1990). The change in the level of acetylcholine is accompanied by changes in EEG activity, where low acetylcholine during sleep is associated with slow-wave activity, and high acetylcholine during the active waking state is associated with theta rhythm in the hippocampus (Green and Arduini, 1954; Winson, 1974). This clearly suggests that the level of acetylcholine modulates neural activity.

Modeling studies have suggested that the hippocampal synaptic network is modified during active waking in such a way that synaptic connections from place cells which fired earlier in the sequence, to those fired later, were potentiated (Jensen and Lisman, 1996; Wallenstein et al., 1998). Since the synaptic transmission usually takes from only a few milliseconds to tens of milliseconds, multiple place cells were activated in a timecompressed sequence during SWS.

A recent study by Dragoi and Tonegawa (2011) may have changed this traditional view that the sequence of place cells only exists after experiences in the maze. This study showed that timecompressed sequential activity of CA1 pyramidal cells during SWS, before the first run in a novel environment, matched well with the sequence of place cell activity during this first run. Such activity during SWS is called "preplay" and this result indicated that the sequential synaptic connections that favored a specific sequence existed even before the rats experienced the new environment, and this existing sequence was used to code the new environment. In other words, place cell firing was strongly influenced by existing synaptic connections, not only during SWS, but also during active waking.

Another line of research that suggests the importance of synaptic connections or internal dynamics during active waking is the "time cell" studies (Pastalkova et al., 2008; MacDonald et al., 2011). In these studies, recordings from sets of CA1 pyramidal cells showed sequential firing during the delay phase of memory tasks. During the delay period, rats were either running in a running wheel (Pastalkova et al., 2008) or waiting in a small confined area (MacDonald et al., 2011). In both tasks, each CA1 pyramidal cell always fired at a specific time after the onset of the delay period. The duration of the "field" was very similar to that of the place cells, and theta phase precession was also observed. Since there seems to be no particular sensory input that changes with time during the delay period, this sequential firing is believed to be generated internally. Although there is no experimental support for this, one hypothesis is that a synaptic network supports this sequential firing.

These recent studies suggest that sequential firing of hippocampal pyramidal cells can be supported by internal mechanisms such as synaptic connections, both in time-compressed scale during SWS and quiet waking, and in real-time scale during active waking. However, to date, it remains unclear how timecompressed (fast) and real-time (slow) sequential activity can be switched. In the next section of the paper, we propose that different levels of acetylcholine in active waking and SWS could modulate the CAN current and that the CAN current sets the temporal scale of sequential activity.

\section{CAN CURRENT-BASED TIME SCALE SWITCH MODEL}

In this conceptual model, we aim to explain the switching between fast and slow sequential activity by taking two cholinergic modulations of cellular properties into account: (1) the modulation of the CAN current and (2) the modulation of synaptic strength. We consider four place cells (or groups of cells, A to D) which have overlapping place fields. Figure 5 shows the activity of these place cells during SWS (Figure 5A) and while running (Figure 5B). Based on the observation by Dragoi and Tonegawa (2011) mentioned above, we assume that these four place cells are sequentially connected through excitatory synapses (A to B, B to C, etc.).

First, in the SWS condition where the acetylcholine level is low, synaptic potential will be relatively large due to the lack of synaptic suppression (Hasselmo, 1999). Therefore, when cell A elicits some action potentials due to random input, this will cause 


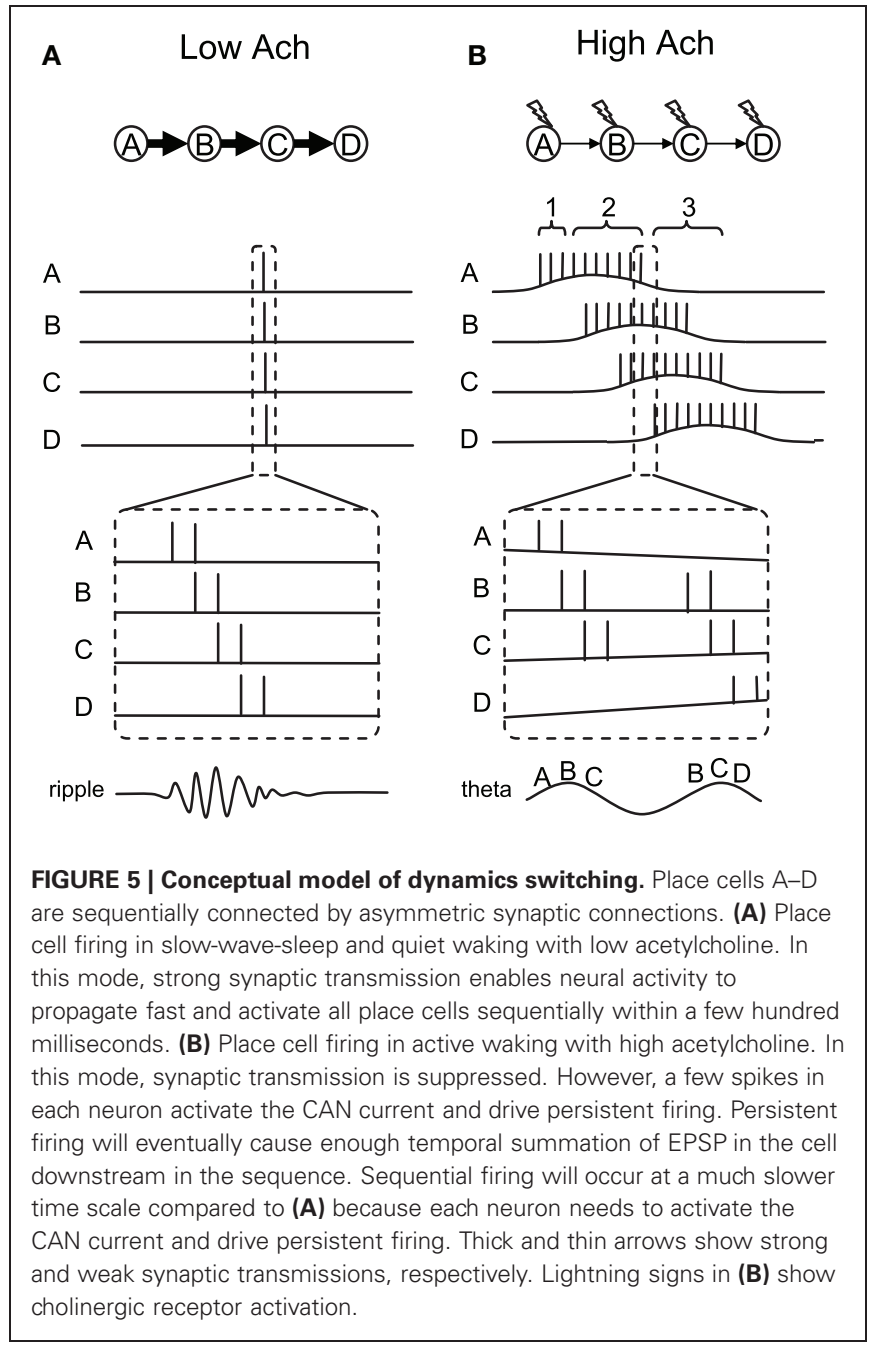

a large excitatory postsynaptic potential (EPSP) in cell B which receives synaptic input from cell $A$. This EPSP will trigger action potentials in cell B. Similarly, cell C and D will fire a couple of action potentials due to propagation of the activity through the synaptic connections. Since synaptic transmission by AMPA and NMDA components takes only from a few to tens of milliseconds, this sequential firing of cells A to D will occur within a few hundreds of milliseconds (duration of one or a few ripples). Because of the low acetylcholine level, action potentials in each cell will not activate the CAN current and, therefore, will not elicit persistent firing (Figure 1A). This fast sequential firing corresponds to replay or preplay during SWS.

Second, in the active waking condition when the acethylcholine level is relatively high, intrinsic synaptic transmission is suppressed (Giocomo and Hasselmo, 2007; Kremin and Hasselmo, 2007), even though the same synaptic connections exist. Therefore, when cell A fires a couple of spikes, this will not provide enough EPSP to immediately trigger firing of cell B (see time indicated by bracket 1 in Figure 5B). However, spikes of cell A will bring calcium into the cell, activate the CAN current and depolarize the membrane to trigger more spikes within cell A (time indicated by bracket 2 in Figure 5B). This does not happen in the absence of acetylcholine, because CAN current activation requires both cholinergic receptor activation and calcium entry, as described earlier. This repetitive firing will eventually cause enough temporal summation of EPSP for cell B to elicit action potentials. Similarly, cells C and D will be activated sequentially. In contrast to the SWS condition, activation of the CAN current in each cell is required for the activity to be propagated to the next cell in the sequence in the active waking stage. Therefore, the sequence is read out slower and each cell fires for a longer duration compared to that in the SWS condition.

As described above, persistent firing driven by the CAN current can be observed either as self-terminating persistent firing (Figure 1C), or long-lasting persistent firing (Figure 1B). If the cells develop self-terminating persistent firing, this model may not require any additional mechanism. However, if the cells develop long-lasting persistent firing, our model needs an additional mechanism to terminate the firing. As described above, long-lasting persistent firing can be terminated by hyperpolarization (Egorov et al., 2002; Navaroli et al., 2011). Such hyperpolarization could be provided by lateral inhibition. For example, for cell A in the model, cell B will not inhibit cell A, but cells C and D will inhibit cell A. This will terminate cell A's firing and deactivate the CAN current.

\section{THETA PHASE PRECESSION}

In vivo electrophysiological recordings show that there is a particular relationship between the spike timing of place cells and the phase of local theta rhythm during active exploration. As the animal enters the place field, place cells initially fire in a late phase of the field theta rhythm, and progressively advance to an earlier phase as the animal goes through the place field (O'Keefe and Recce, 1993; Skaggs et al., 1996). This phenomenon is called "phase precession" and this can also be seen in our conceptual model. First of all, neurons tend to fire in a theta frequency range during CAN current-driven persistent firing. Therefore, we assume that neurons in our model fire in a theta frequency within its place field. Here, we explain the precession using Figure 5B, where one part of the activity within the dashed lines is magnified at the bottom.

Although synaptic connections are suppressed during active waking, EPSPs still exist to a smaller degree. Therefore, when two neurons (for example A and B) fire at locations where their fields overlap, neuron B will more likely spike on top of the EPSP due to the spiking of cell A. This causes cells that are in their overlapping place fields to fire sequentially within a theta cycle, in a timecompressed mode, as shown in in vivo data (Skaggs et al., 1996). This can be imagined as place cells $\mathrm{A}, \mathrm{B}$, and $\mathrm{C}$ firing sequentially in a time-compressed mode in every theta cycle as long as the animal's location is where those three fields overlap. However, as the animal walks toward the place field D, place cell D starts firing. At the same time, place cell A may stop firing since the animal is now outside the place field A. As a result, the time-compressed sequence of A-B-C will now change to B-C-D. The dashed lines in Figure 5B depict this shift from sequence A-B-C to B-C-D. The left half of the figure shows the activity of the cells at the end of the place field A, before the place cell D starts to fire. In this case, cells A-B-C fire sequentially as shown by the letters at the bottom of the 
magnified traces. The right half of the figure shows the activity of the cells immediately after this, where place cell A stops firing and place cell D starts firing. In this case, cells B-C-D fire sequentially. As a result, the firing order of cell $\mathrm{B}$, for example, precessed from second place in A-B-C to first place in B-C-D. This mechanism, therefore, allows place cells to shift their firing order toward an earlier position among the population of place cells that are currently firing, due to an overlap of place fields as the animal runs through the field.

We next argue that an earlier firing position in the population of cells is linked to theta phase precession, using the illustrated theta wave at the bottom of Figure 5B. As pointed out by Geisler et al. (2010), field theta rhythm could reflect population activity of neurons. This means that the population of place cells that is currently firing, due to overlapping place fields, sets the theta rhythm. In our model, this population of cells is, for example, cells A-B-C, where the firing timing of place cells A, B, and C correspond to early, mid and late phase of field theta rhythm, respectively. The illustrated theta rhythm in Figure 5B (bottom) reflects the population activity. Since place cells that are in the middle of their place fields fire more spikes than others, the resulting field potential increases toward the middle of the sequence. For example, when the animal is in the middle of place field $\mathrm{B}$, place cell B fires with a higher frequency than other cells and causes a peak of the theta rhythm (Figure 5B bottom left). When the population of cells changes from A-B-C to B-C-D, firing of place cell $\mathrm{B}$ now corresponds to an early phase of the field theta rhythm (Figure 5B, bottom right). Firing of cell B, for example, therefore shifts from the later phase of theta to the earlier phase of theta. Our model shows theta phase precession in a similar way to that proposed by Geisler et al. (2010).

\section{DIFFERENCE FROM ATTRACTOR-NETWORK MODEL}

The active waking stage in our model is similar to the attractornetwork model of place cells in that both models have an ability to maintain activity of groups of neurons. The means to maintain activity is, however, different. While most attractor-network models rely on an excitatory recurrent network among cells, our model relies on the CAN current activation, which is intrinsic to many types of cells in the MTL. While dense excitatory recurrent connections are found in the hippocampal CA3 area, such excitatory connection in CA1 or EC layer II does not seem to be abundant (Tamamaki and Nojyo, 1990; Witter and Amaral, 1991; Kumar et al., 2007; Quilichini et al., 2010). Our model does not rely on excitatory recurrent connections to produce a bump of activity; rather it uses recurrent connections to code sequences. Therefore, less excitatory recurrent connections available in the CA1 area may not be enough for the maintenance of the bump activity. However, it could still be enough to code the sequence when the maintenance of activity is done by the CAN current which is intrinsic to individual cells.

In addition, while the attractor model is prone to the problem of runaway excitation, and often needs global inhibition to keep the cellular activity in a reasonable firing frequency range, the CAN current bump could be relatively resistant to the problem of runaway excitation, since the amount of CAN current limits the maximum firing frequency in individual neurons.

\section{AWAKE REPLAY}

It has been shown that ripple activity occurs during quiet waking, as well as in SWS, and temporally compressed replay of either forward or backward sequence can be observed during ripples (Foster and Wilson, 2006). As described earlier, the acetylcholine level is reported to decrease during quiet waking. Recent observations of acetylcholine level measurements show that the acetylcholine level can be modulated in the order of seconds in the prefrontal cortex (Parikh et al., 2007). Network dynamics could, therefore, be set for time-compressed replay transiently during quiet waking. As for the direction of replay, our model can account for this if we assume that the synaptic connections are strengthened both in forward (A-B-C-D) and backward directions (D-C-B-A). Such connections could be realistic due to modified spike-timing-dependent synaptic plasticity (STDP) in high acetylcholine levels (Sugisaki et al., 2011). This study has shown that the STDP protocol causes LTP both at positive and negative spike timing in high acetylcholine levels. Such an STDP rule could possibly form a bi-directionally strengthened sequence of cells during a run, and support reversed replay in the quiet awake stage after the run.

\section{INCREASED GRID CELL SPACING IN NOVEL ENVIRONMENTS}

Preliminary data by Barry et al. (2009) has shown that grid cell spacing increases in a novel environment. As the concentration of acetylcholine is further elevated in a novel environment (Giovannini et al., 2001), a larger grid size could be related to higher cholinergic activation. Here we discuss this possibility in a grid cell model proposed by Navratilova et al. (2011) and in our own model.

The grid cell model by Navratilova et al. (2011) used an ADP current for activation of grid cells at different timings from that of field theta oscillation, in each theta cycle. As a result, the time constant of the ADP current defined the grid cell spacing. In this model, higher cholinergic activity in a novel environment may modulate the grid cell spacing through a modification of the ADP time constant in two possible ways. First, the slower membrane resonance frequency, due to the modulation of the $\mathrm{H}$-current in higher cholinergic activity (Heys et al., 2010), may contribute to slowing the ADP time constant. Second, activation of the CAN current, which has delayed activation peak (Magistretti et al., 2004), could contribute to delaying the ADP peak. Both of these mechanisms could increase the grid spacing in this model.

In the model presented in this paper, however, the CAN current supported slow in-field depolarization, and the interaction between the CAN current and the theta rhythm was not considered. In our model, a larger CAN current conductance, and a greater suppression of excitatory synaptic connections, may cause greater grid cell spacing. First, the larger CAN current conductance may cause increased persistent firing of individual neurons, resulting in longer in-field firing duration. Second, further reduction of synaptic excitability may delay the activation of the next cell in the sequence. Even though our model is not a grid cell model, this mechanism could result in a larger grid cell spacing if our model is formed as a ring, as in the Navratilova et al. (2011) model. 


\section{DISCUSSION}

In this paper we have shown that activation of the CAN current supports persistent firing in many types of neurons in the MTL. Persistent firing enables each cell to maintain its previous input by sustained firing. We, and others, suggest this feature could be directly useful for the short-term memory function of the MTL. Furthermore, we suggest that persistent firing could be useful for the attractor-network model, especially when local excitatory recurrent synaptic connections are limited. We demonstrated that mechanisms for persistent firing may underlie activity of place cells during active waking. This is consistent with a study which has shown that cholinergic suppression greatly reduces the firing frequency of place cells (Brazhnik et al., 2003). Finally, we have proposed that the network activity switches from real-time to time-compressed replay mode as the acetylcholine level drops and suppresses the CAN current.

It has been proposed that the MTL, especially the hippocampus, is crucial for bridging the temporal gap (Wallenstein et al., 1998; Howard et al., 2005; Naya and Suzuki, 2011). In theory, it is possible to divide a linear maze, $1 \mathrm{~m}$ in length, into 1000 $1 \mathrm{~mm}$ bins, and code all these locations with 1000 place cells, whose place fields are $1 \mathrm{~mm}$ long. This way, if a rat takes $5 \mathrm{~s}$ to walk through this maze, at least 1000 place cells will fire with a $5 \mathrm{~ms}$ interval between neurons. Since $5 \mathrm{~ms}$ is an optimal timing to induce LTP through STDP, this trajectory could be encoded successfully. In this case, the CAN current does not seem to be required.

However, a potential problem of this approach is costly and slow sequential recall ability. It has been reported that hippocampal CA3 place cells transiently encode paths forward of the animal at a choice point of a T-maze (Johnson and Redish, 2007). This is seen as a set of CA3 place cells that have place fields ahead of the animal to fire in a time-compressed mode, typically within one theta cycle $(<200 \mathrm{~ms})$. It is suggested that this activity is recalling possible future locations for planning future trajectories or for decision-making at a choice point (Johnson and Redish, 2007). If we assume that a $1 \mathrm{~m}$ long path is coded by 1000 sequentially connected place cells, without the aid of the CAN current, as described above, retrieval of the future $1 \mathrm{~m}$ long path, using the current location as the cue signal, will require activation of 1000 neurons. This will take $5 \mathrm{~s}$, if we assume that glutamatergic synaptic transmission allows the propagation of activity in the chain of 1000 place cells with the delay of $5 \mathrm{~ms}$ in each pair of cells. Therefore, planning of the future trajectory may take the same amount of time as the animal actually takes to run along the

\section{REFERENCES}

Ainge, J. A., van der Meer, M. A., Langston, R. F., and Wood, E. R. (2007). Exploring the role of context-dependent hippocampal activity in spatial alternation behavior. Hippocampus 17, 988-1002.

Anagnostaras, S. G., Murphy, G. G., Hamilton, S. E., Mitchell, S. L., Rahnama, N. P., Nathanson,
N. M., and Silva, A. J. (2003). Selective cognitive dysfunction in acetylcholine M1 muscarinic receptor mutant mice. Nat. Neurosci. 6, 51-58.

Andrade, R. (1991). Cell excitation enhances muscarinic cholinergic responses in rat association cortex. Brain Res. 548, 81-93.

Arnold, H. M., Burk, J. A., Hodgson, E. M., Sarter, M., and Bruno, J. trajectory. This would not be the best strategy, especially when the animal needs to plan a future path based on memory, to escape from a predator and to survive.

One way to solve this problem is to make the sequential firing during the encoding stage intentionally slow. This will provide the possibility to perform faster-than-real-time recall using a physiological mechanism. The model we proposed in this article used CAN current activation and synaptic suppression to achieve this slow dynamics during active waking. We believe that this is a physiologically plausible mechanism, particularly because the acetylcholine level is known to control the sequential firing speed (fast and slow), the CAN current and synaptic transmission.

Another possible benefit of this model comes from the longer duration firing of each place cell during active waking. Longduration firing increases the chance for two place cells, with their center of field being far apart, to fire together, overlapping in time. This overlap will enable them to induce Hebbian synaptic plasticity. Therefore, there is no need to code location in $1 \mathrm{~mm}$ bins, which can reduce the number of place cells necessary to code $1 \mathrm{~m}$ of distance. Finally, this model could be applied to tasks other than spatial navigation. For example, we have an ability to recall a sequence of episodic memories, such as how we traveled from home to work in the morning, in a few seconds. This type of recall, which occurs faster than real-time, might be possible because of slowly changing hippocampal activity during acquisition of episodic memory.

As noted earlier, hippocampal CA1 cells show sequential firing during the delay period of some tasks that do not involve apparent spatial movements ("time cell," Pastalkova et al., 2008; MacDonald et al., 2011). Since animals perceive similar sensory input throughout the delay period, the existence of sequential firing indicates internal dynamics (Pastalkova et al., 2008). Our model, which requires only an initial cue to start sequential firing of cell A to D in active waking mode (Figure 5B), would also explain "time cell" firing. Although replay or preplay of time cells have not yet been reported, this model predicts that they would also show replay or preplay.

An interesting detail of time cell firing is that the "time field" for cells that fire later in the sequence tends to be longer than that of those that fire earlier in the sequence (MacDonald et al., 2011). Our model could explain this as follows: cells that fire early in the sequence are effectively inhibited by the lateral inhibition mechanism, described earlier, through activation of cells that fire later in the sequence. In contrast, cells that fire later in the sequence do not receive as much inhibition since fewer cells subsequently fire.
P. (2002). Differential cortical acetylcholine release in rats performing a sustained attention task versus behavioral control tasks that do not explicitly tax attention. Neuroscience 114, 451-460.

Bang, S. J., and Brown, T. H. (2009). Perirhinal cortex supports acquired fear of auditory objects. Neurobiol. Learn. Mem. 92, 53-62.
Bangasser, D. A., Waxler, D. E., Santollo, J., and Shors, T. J. (2006). Trace conditioning and the hippocampus: the importance of contiguity. J. Neurosci. 26, 8702-8706.

Barry, C., O'Keefe, J., and Burgess, N. (2009). Effect of novelty on grid cell firing. Soc. Neurosci. Abstr. 35, 101-124.

Benardo, L. S., and Prince, D. A. (1982a). Cholinergic excitation of 
mammalian hippocampal pyramidal cells. Brain Res. 249, 315-331.

Benardo, L. S., and Prince, D. A. (1982b). Ionic mechanisms of cholinergic excitation in mammalian hippocampal pyramidal cells. Brain Res. 249, 333-344.

Bird, C. M., and Burgess, N. (2008). The hippocampus and memory: insights from spatial processing. Nat. Rev. Neurosci. 9, 182-194.

Boccara, C. N., Sargolini, F., Thoresen, V. H., Solstad, T., Witter, M. P., Moser, E. I., and Moser, M. B. (2010). Grid cells in pre- and parasubiculum. Nat. Neurosci. 13, 987-994.

Boucheny, C., Brunel, N., and Arleo, A. (2005). A continuous attractor network model without recurrent excitation: maintenance and integration in the head direction cell system. J. Comput. Neurosci. 18, 205-227.

Brandon, M. P., Bogaard, A. R., Libby, C. P., Connerney, M. A., Gupta, K., and Hasselmo, M. E. (2011). Reduction of theta rhythm dissociates grid cell spatial periodicity from directional tuning. Science 332, 595-599.

Brazhnik, E. S., Muller, R. U., and Fox, S. E. (2003). Muscarinic blockade slows and degrades the locationspecific firing of hippocampal pyramidal cells. J. Neurosci. 23, 611-621.

Buzsáki, G. (1989). Two-stage model of memory trace formation: a role for "noisy" brain states. Neuroscience $31,551-570$.

Caeser, M., Brown, D. A., Gähwiler, B. H., and Knöpfel, T. (1993). Characterization of a calciumdependent current generating a slow afterdepolarization of CA3 pyramidal cells in rat hippocampal slice cultures. Eur. J. Neurosci. 5, 560-569.

Cashdollar, N., Malecki, U., RuggGunn, F. J., Duncan, J. S., Lavie, N., Duzel, E. (2009). Hippocampusdependent and -independent thetanetworks of active maintenance. Proc. Natl. Acad. Sci. U.S.A. 106, 20493-20498.

Cole, A. E., and Nicoll, R. A. (1983). Acetylcholine mediates a slow synaptic potential in hippocampalpyramidal cells. Science 221, 1299-1301.

Colombo, M., and Gross, C. G. (1994). Responses of inferior temporal cortex and hippocampal neurons during delayed matching to sample in monkeys (Macaca fascicularis). Behav. Neurosci. 108, 443-455.
Deadwyler, S. A., and Hampson, R. E. (2004). Differential but complementary mnemonic functions of the hippocampus and subiculum. Neuron 42, 465-476.

Dragoi, G., and Tonegawa, S. (2011). Preplay of future place cell sequences by hippocampal cellular assemblies. Nature 469, 397-401.

Egorov, A. V., Hamam, B. N., Fransén, E., Hasselmo, M. E., and Alonso, A. A. (2002). Graded persistent activity in entorhinal cortex neurons. Nature 420, 173-178.

Egorov, A. V., Unsicker, K., and von Bohlen und Halbach, O. (2006) Muscarinic control of graded persistent activity in lateral amygdala neurons. Eur. J. Neurosci. 24 3183-3194.

Esclassan, F., Coutureau, E., Di Scala, G., and Marchand, A. R. (2009). A cholinergic-dependent role for the entorhinal cortex in trace fear conditioning. J. Neurosci. 29, 8087-8093.

Farovik, A., Dupont, L. M., and Eichenbaum, H. (2009). Distinct roles for dorsal CA3 and CA1 in memory for sequential nonspatial events. Learn. Mem. 17, 12-17.

Foster, D. J., and Wilson, M. A. (2006). Reverse replay of behavioural sequences in hippocampal place cells during the awake state. Nature $440,680-683$.

Fransén, E., Alonso, A. A., and Hasselmo, M. E. (2002). Simulations of the role of the muscarinic-activated calciumsensitive nonspecific cation current INCM in entorhinal neuronal activity during delayed matching tasks. J. Neurosci. 22, 1081-1097.

Fraser, D. D., and MacVicar, B. A. (1996). Cholinergic-dependent plateau potential in hippocampal CA1 pyramidal neurons. J. Neurosci. 16, 4113-4128.

Garden, D. L., Dodson, P. D., O'Donnell, C., White, M. D. and Nolan, M. F. (2008). Tuning of synaptic integration in the medial entorhinal cortex to the organization of grid cell firing fields. Neuron $60,875-889$.

Gähwiler, B. H., and Dreifuss, J. J. (1982). Multiple actions of acetylcholine on hippocampal pyramidal cells in organotypic explant cultures. Neuroscience 7, 1243-1256.

Geisler, C., Diba, K., Pastalkova, E., Mizuseki, K., Royer, S., and Buzsáki, G. (2010). Temporal delays among place cells determine the frequency of population theta oscillations in the hippocampus.
Proc. Natl. Acad. Sci. U.S.A. 107, 7957-7962.

Gilbert, P. E., and Kesner, R. P. (2002) Role of the rodent hippocampus in paired-associate learning involving associations between a stimulus and a spatial location. Behav. Neurosci. 116, 63-71.

Gilbert, P. E., Kesner, R. P., and Lee, I. (2001). Dissociating hippocampal subregions: double dissociation between dentate gyrus and CA1. Hippocampus 11, 626-636.

Giocomo, L. M., and Hasselmo, M. E. (2007). Neuromodulation by glutamate and acetylcholine can change circuit dynamics by regulating the relative influence of afferent input and excitatory feedback. Mol. Neurobiol. 36, 184-200.

Giocomo, L. M., Zilli, E. A., Fransén, E., and Hasselmo, M. E. (2007). Temporal frequency of subthreshold oscillations scales with entorhinal grid cell field spacing. Science 315 , 1719-1722.

Giocomo, L. M., Moser, M. B., and Moser, E. I. (2011). Computational models of grid cells. Neuron 71, 589-603.

Giovannini, M. G., Rakovska, A., Benton, R. S., Pazzagli, M., Bianchi, L., and Pepeu, G. (2001). Effects of novelty and habituation on acetylcholine, GABA, and glutamate release from the frontal cortex and hippocampus of freely moving rats. Neuroscience 106, 43-53.

Goodridge, J. P., Dudchenko, P. A., Worboys, K. A., Golob, E. J., and Taube, J. S. (1998). Cue control and head direction cells. Behav. Neurosci. 112, 749-761.

Goodridge, J. P., and Touretzky, D. S. (2000). Modeling attractor deformation in the rodent headdirection system. J. Neurophysiol. 83, 3402-3410.

Green, J. D., and Arduini, A. A. (1954). Hippocampal electrical activity and arousal. J. Neurophysiol. 17, 533-557.

Hafting, T., Fyhn, M., Molden, S., Moser, M. B., and Moser, E. I. (2005). Microstructure of a spatial map in the entorhinal cortex. Nature 436, 801-806.

Halliwell, J. V., and Adams, P. R. (1982). Voltage-clamp analysis of muscarinic excitation in hippocampal neurons. Brain Res. 250, 71-92.

Hampson, R. E., Pons, T. P., Stanford, T. R., and Deadwyler, S. A. (2004). Categorization in the monkey hippocampus: a possible mechanism for encoding information into memory. Proc. Natl. Acad. Sci. U.S.A. 101, 3184-3189.
Hannula, D. E., Tranel, D., and Cohen, N. J. (2006). The long and the short of it: relational memory impairments in amnesia, even at short lags. J. Neurosci. 26, 8352-8359.

Hartley, T., Bird, C. M., Chan, D., Cipolotti, L., Husain, M., VarghaKhadem, F., and Burgess, N. (2007). The hippocampus is required for short-term topographical memory in humans. Hippocampus 17, 34-48.

Hasselmo, M. E. (1999). Neuromodulation: acetylcholine and memory consolidation. Trends Cogn. Sci. 3, 351-359.

Hasselmo, M. E. (2007). Arc length coding by interference of theta frequency oscillations may underlie context-dependent hippocampal unit data and episodic memory function. Learn. Mem. 14, 782-794.

Hasselmo, M. E., Giocomo, L. M., Brandon, M. P., and Yoshida, M. (2010). Cellular dynamical mechanisms for encoding the time and place of events along spatiotemporal trajectories in episodic memory. Behav. Brain Res. 215, 261-274.

Hasselmo, M. E., and Schnell, E. (1994). Laminar selectivity of the cholinergic suppression of synaptic transmission in rat hippocampal region CA1: computational modeling and brain slice physiology. J. Neurosci. 14, 3898-3914.

Heys, J. G., Giocomo, L. M., and Hasselmo, M. E. (2010). Cholinergic modulation of the resonance properties of stellate cells in layer II of medial entorhinal cortex. J. Neurophysiol. 104, 258-270.

Himmelheber, A. M., Sarter, M., and Bruno, J. P. (2001). The effects of manipulations of attentional demand on cortical acetylcholine release. Brain Res. Cogn. Brain Res. $12,353-370$.

Howard, M. W., Fotedar, M. S., Datey, A. V., and Hasselmo, M. E. (2005) The temporal context model in spatial navigation and relational learning: toward a common explanation of medial temporal lobe function across domains. Psychol. Rev. 112, 75-116.

Jensen, O., and Lisman, J. E. (1996). Theta/gamma networks with slow NMDA channels learn sequences and encode episodic memory: role of NMDA channels in recall. Learn. Mem. 3, 264-278.

Johnson, A., and Redish, A. D. (2007). Neural ensembles in CA3 transiently encode paths forward of the animal at a decision point J. Neurosci. 27, 12176-12189. 
Kametani, H., and Kawamura, H. (1990). Alterations in acetylcholine release in the rat hippocampus during sleep-wakefulness detected by intracerebral dialysis. Life Sci. 47, 421-426.

Kawasaki, H., Palmieri, C., and Avoli, M. (1999). Muscarinic receptor activation induces depolarizing plateau potentials in bursting neurons of the rat subiculum. J. Neurophysiol. 82, 2590-2601.

Kesner, R. P., Hunsaker, M. R., and Gilbert, P. E. (2005). The role of $\mathrm{CAl}$ in the acquisition of an objecttrace-odor paired associate task. Behav. Neurosci. 119, 781-786.

Kholodar-Smith, D. B., Boguszewski, P., and Brown, T. H. (2008). Auditory trace fear conditioning requires perirhinal cortex. Neurobiol. Learn. Mem. 90, 537-543.

Kim, J. J., Clark, R. E., and Thompson, R. F. (1995). Hippocampectomy impairs the memory of recently, but not remotely, acquired trace eyeblink conditioned responses. Behav. Neurosci. 109, 195-203.

Klink, R., and Alonso, A. (1997). Muscarinic modulation of the oscillatory and repetitive firing properties of entorhinal cortex layer II neurons. J. Neurophysiol. 77, 1813-1828.

Koene, R. A., and Hasselmo, M. E. (2008). Reversed and forward buffering of behavioral spike sequences enables retrospective and prospective retrieval in hippocampal regions CA3 and CA1. Neural Netw. 21, 276-288.

Koenig, J., Linder, A. N., Leutgeb, J. K., and Leutgeb, S. (2011). The spatial periodicity of grid cells is not sustained during reduced theta oscillations. Science 332, 592-595.

Kremin, T., and Hasselmo, M. E. (2007). Cholinergic suppression of glutamatergic synaptic transmission in hippocampal region CA3 exhibits laminar selectivity: implication for hippocampal network dynamics. Neuroscience 149, 760-767.

Kumar, S. S., Jin, X., Buckmaster, P. S., and Huguenard, J. R. (2007). Recurrent circuits in layer II of medial entorhinal cortex in a model of temporal lobe epilepsy. J. Neurosci. 27, 1239-1246.

Lee, A. K., and Wilson, M. A. (2002). Memory of sequential experience in the hippocampus during slow wave sleep. Neuron 36, 1183-1194.

Lisman, J., and Idiart, M. (1995). Storage of $7 \pm 2$ short-term memories in oscillatory subcylces. Science 267, 1512-1515.

MacDonald, C. J., Lepage, K. Q., Eden, U. T., and Eichenbaum, H. (2011). Hippocampal "time cells" bridge the gap in memory for discontiguous events. Neuron 71, 737-749.

Madison, D. V., Lancaster, B., and Nicoll, R. A. (1987). Voltage clamp analysis of cholinergic action in the hippocampus. J. Neurosci. 7 , 733-741.

Magistretti, J., Ma, L., Shalinsky, M. H., Lin, W., Klink, R., and Alonso, A. (2004). Spike patterning by Ca2+-dependent regulation of a muscarinic cation current in entorhinal cortex layer II neurons. J. Neurophysiol. 92, 1644-1657.

Major, G., and Tank, D. (2004). Persistent neural activity: prevalence and mechanisms. Curr. Opin. Neurobiol. 14, 675-684.

Marrosu, F., Portas, C., Mascia, M. S., Casu, M. A., Fà, M., Giagheddu, M., Imperato, A., and Gessa, G. L. (1995). Microdialysis measurement of cortical and hippocampal acetylcholine release during sleep-wake cycle in freely moving cats. Brain Res. 671, 329-332.

McClelland, J. L., McNaughton, B. L., and O'Reilly, R. C. (1995). Why there are complementary learning systems in the hippocampus and neocortex: insights from the successes and failures of connectionist models of learning and memory. Psychol. Rev. 102, 419-457.

McEchron, M. D., Tseng, W., and Disterhoft, J. F. (2000). Neurotoxic lesions of the dorsal hippocampus disrupt auditory-cued trace heart rate (fear) conditioning in rabbits. Hippocampus 10, 739-751.

McEchron, M. D., Tseng, W., and Disterhoft, J. F. (2003). Single neurons in CAl hippocampus encode trace interval duration during trace heart rate (fear) conditioning in rabbit. J. Neurosci. 23 , 1535-1547.

McEchron, M. D., Weible, A. P., and Disterhoft, J. F. (2001). Aging and learning-specific changes in singleneuron activity in CA1 hippocampus during rabbit trace eyeblink conditioning. J. Neurophysiol. 86, 1839-1857.

McGaugh, J. L. (2000). Memory-a century of consolidation. Science 287, 248-251.

McGaughy, J., Koene, R. A., Eichenbaum, H., and Hasselmo, M. E. (2005). Cholinergic deafferentation of the entorhinal cortex in rats impairs encoding of novel but not familiar stimuli in a delayed nonmatch-to-sample task. J. Neurosci. 25, 10273-10281.

McNaughton, B. L., Battaglia, F. P., Jensen, O., Moser, E. I., and Moser, M. B. (2006). Path integration and the neural basis of the 'cognitive map'. Nat. Rev. Neurosci. 7, 663-678.

McNaughton, B. L., Chen, L. L., and Markus, E. J. (1991). Dead reckoning, landmark learning, and the sense of direction-a neurophysiological and computational hypothesis. J. Cogn. Neurosci. 3, 192-202.

Mikulka, P. J., and Freeman, F. G. (1975). The effects of reinforcement delay and hippocampal lesions on the acquisition of a choice response. Behav. Biol. 15, 473-477.

Mizumori, S. J., McNaughton, B. L., Barnes, C. A., and Fox, K. B. (1989). Preserved spatial coding in hippocampal CA1 pyramidal cells during reversible suppression of $\mathrm{CA} 3 \mathrm{C}$ output: evidence for pattern completion in hippocampus. J. Neurosci. 9, 3915-3928.

Molter, C., Sato, N., and Yamaguchi, Y. (2007). Reactivation of behavioral activity during sharp waves: a computational model for two stage hippocampal dynamics. Hippocampus 17, 201-209.

Moser, E. I., Kropff, E., and Moser M. B. (2008). Place cells, grid cells, and the brain's spatial representation system. Annu. Rev. Neurosci. 31, 69-89.

Muller, R. U., Bostock, E., Taube, J. S., and Kubie, J. L. (1994). On the directional firing properties of hippocampal place cells. J. Neurosci. 14 7235-7251.

Navratilova, Z., Giocomo, L. M., Fellous, J. M., Hasselmo, M. E. and McNaughton, B. L. (2011). Phase precession and variable spatial scaling in a periodic attractor map model of medial entorhinal grid cells with realistic after-spike dynamics. Hippocampus. (in print).

Navaroli, V. L., Zhao, Y., Boguszewski, P., and Brown, T. H. (2011) Muscarinic receptor activation enables persistent firing in pyramidal neurons from superficial layers of dorsal perirhinal cortex. Hippocampus. (in print).

Naya, Y., and Suzuki, W. A. (2011). Integrating what and when across the primate medial temporal lobe. Science 333, 773-776.

O'Keefe, J., and Burgess, N. (2005). Dual phase and rate coding in hippocampal place cells: theoretical significance and relationship to entorhinal grid cells. Hippocampus 15, 853-866.
O'Keefe, J., and Dostrovsky, J. (1971). The hippocampus as a spatial map. Preliminary evidence from unit activity in the freely-moving rat. Brain Res. 34, 171-175.

O'Keefe, J., and Recce, M. L. (1993). Phase relationship between hippocampal place units and the EEG theta rhythm. Hippocampus 3, 317-330.

Olsen, R. K., Nichols, E. A., Chen, J., Hunt, J. F., Glover, G. H., Gabrieli, J. D., and Wagner, A. D. (2009). Performance-related sustained and anticipatory activity in human medial temporal lobe during delayed matchto-sample. J. Neurosci. 29, 11880-11890.

Olson, I. R., Moore, K. S., Stark, M., and Chatterjee, A. (2006). Visual working memory is impaired when the medial temporal lobe is damaged. J. Cogn. Neurosci. 18 1087-1097.

Otto, T., and Eichenbaum, H. (1992a). Neuronal activity in the hippocampus during delayed non-match to sample performance in rats: evidence for hippocampal processing in recognition memory. Hippocampus 2, 323-334.

Otto, T., and Eichenbaum, H. (1992b). Complementary roles of the orbital prefrontal cortex and the perirhinal-entorhinal cortices in an odor-guided delayed-nonmatchingto-sample task. Behav. Neurosci. 106, 762-775.

Pang, M. H., Kim, N. S., Kim, I. H. Kim, H., Kim, H. T., and Choi, J. S. (2010). Cholinergic transmission in the dorsal hippocampus modulates trace but not delay fear conditioning. Neurobiol. Learn. Mem. 94, 206-213.

Parikh, V., Kozak, R., Martinez, V., and Sarter, M. (2007). Prefrontal acetylcholine release controls cue detection on multiple timescales. Neuron 56, 141-154.

Pastalkova, E., Itskov, V., Amarasingham, A., and Buzsáki, G. (2008). Internally generated cell assembly sequences in the rat hippocampus. Science 321, 1322-1327.

Penetar, D. M., McDonough, J. H. Jr. (1983). Effects of cholinergic drugs on delayed match-to-sample performance of rhesus monkeys. Pharmacol. Biochem. Behav. 19, 963-967.

Quilichini, P., Sirota, A., and Buzsáki, G. (2010). Intrinsic circuit organization and theta-gamma oscillation dynamics in the entorhinal cortex of the rat. J. Neurosci. 30, 11128-11142. 
Quirk, G. J., Muller, R. U., and Kubie, J. L. (1990). The firing of hippocampal place cells in the dark depends on the rat's recent experience. J. Neurosci. 10, 2008-2017.

Ranck, J. J. (1984). Head direction cells in the deep layer of dorsal presubiculum in freely moving rats. Soc. Neurosci. Abstr. 10, 599.

Rawlins, J. N., Feldon, J., and Butt, S. (1985). The effects of delaying reward on choice preference in rats with hippocampal or selective septal lesions. Behav. Brain Res. 15, 191-203.

Reboreda, A., Jiménez-Díaz, L., and Navarro-López, J. D. (2011). TRP channels and neural persistent activity. Adv. Exp. Med. Biol. 704, 595-613.

Reboreda, A., Raouf, R., Alonso, A., and Séguéla, P. (2007). Development of cholinergic modulation and graded persistent activity in layer $\mathrm{v}$ of medial entorhinal cortex. J. Neurophysiol. 97, 3937-3947.

Redish, A., Elga, A., and Touretzky, D. (1996). A coupled attractor model of the rodent head direction system. Network 7, 671-685.

Rubin, J., Terman, D., and Chow, C. (2001). Localized bumps of activity sustained by inhibition in a two-layer thalamic network. J. Comput. Neurosci. 10, 313-331.

Sargolini, F., Fyhn, M., Hafting, T., McNaughton, B. L., Witter, M. P., Moser, M. B., and Moser, E. I. (2006). Conjunctive representation of position, direction, and velocity in entorhinal cortex. Science 312, 758-762.

Schon, K., Atri, A., Hasselmo, M. E., Tricarico, M. D., LoPresti, M. L., and Stern, C. E. (2005). Scopolamine reduces persistent activity related to long-term encoding in the parahippocampal gyrus during delayed matching in humans. J. Neurosci. 25, 9112-9123.

Schon, K., Hasselmo, M. E., Lopresti, M. L., Tricarico, M. D., and Stern, C. E. (2004). Persistence of parahippocampal representation in the absence of stimulus input enhances long-term encoding: a functional magnetic resonance imaging study of subsequent memory after a delayed matchto-sample task. J. Neurosci. 24, 11088-11097.

Segal, M. (1982). Multiple action of acetylcholine at a muscarinic receptor studied in the rat hippocampal slice. Brain Res. 246, 77-87.
Skaggs, W. E., Knierim, J. J., Kudrimoti, H. S., and McNaughton, B. L. (1995). A model of the neural basis of the rat's sense of direction. Adv. Neural Inf. Process. Syst. 7 173-180.

Skaggs, W. E., McNaughton, B. L., Wilson, M. A., and Barnes, C. A. (1996). Theta phase precession in hippocampal neuronal populations and the compression of temporal sequences. Hippocampus 6, 149-172.

Sharp, P. E. (1996). Multiple spatial/behavioral correlates for cells in the rat postsubiculum: multiple regression analysis and comparison to other hippocampal areas. Cereb. Cortex 6, 238-259.

Sheffield, M. E., Best, T. K., Mensh, B. D., Kath, W. L., and Spruston, N. (2011). Slow integration leads to persistent action potential firing in distal axons of coupled interneurons. Nat. Neurosci. 14, 200-207.

Shen, B., and McNaughton, B. L. (1996). Modeling the spontaneous reactivation of experience-specific hippocampal cell assembles during sleep. Hippocampus 6, 685-692.

Shu, Y., Hasenstaub, A., and McCormick, D. A. (2003). Turning on and off recurrent balanced cortical activity. Nature 423 288-293.

Solomon, P. R., Vander Schaaf, E. R., Thompson, R. F., and Weisz, D. J. (1986). Hippocampus and trace conditioning of the rabbit's classically conditioned nictitating membrane response. Behav. Neurosci. 100, 729-744.

Song, P., and Wang, X. J. (2005) Angular path integration by moving "hill of activity": a spiking neuron model without recurrent excitation of the headdirection system. J. Neurosci. 25, 1002-1014.

Squire, L. R. (1992). Memory and the hippocampus: a synthesis from findings with rats, monkeys, and humans. Psychol. Rev. 99, 195-231.

Squire, L. R., and Zola-Morgan, S. (1991). The medial temporal lobe memory system. Science 253, 1380-1386.

Storm, J. F. (1989). An afterhyperpolarization of medium duration in rat hippocampal pyramidal cells. J. Physiol. 409, 171-190.

Sugisaki, E., Fukushima, Y., Tsukada, M., and Aihara, T. (2011). Cholinergic modulation on spike timing-dependent plasticity in hippocampal CA1 network. Neuroscience 192, 91-101.
Suzuki, W. A., Miller, E. K., and Desimone, R. (1997). Object and place memory in the macaque entorhinal cortex. J. Neurophysiol. 78, 1062-1081.

Tahvildari, B., Alonso, A. A., and Bourque, C. W. (2008). Ionic basis of ON and OFF persistent activity in layer III lateral entorhinal cortical principal neurons. J. Neurophysiol. 99, 2006-2011.

Tahvildari, B., Fransén, E., Alonso, A. A., and Hasselmo, M. E. (2007). Switching between "On" and "Off" states of persistent activity in lateral entorhinal layer III neurons. Hippocampus 17, 257-263.

Tai, C., Hines, D. J., Choi, H. B. and Macvicar, B. A. (2010). Plasma membrane insertion of TRPC5 channels contributes to the cholinergic plateau potential in hippocampal CA1 pyramidal neurons. Hippocampus. 21, 958-967.

Tamamaki, N., and Nojyo, Y. (1990). Disposition of the slab-like modules formed by axon branches originating from single CAl pyramidal neurons in the rat hippocampus. J. Comp. Neurol. 291 509-519.

Taube, J. S., Muller, R. U., Ranck, J. B. Jr. (1990a). Head-direction cells recorded from the postsubiculum in freely moving rats. I. Description and quantitative analysis. J. Neurosci. 10 420-435.

Taube, J. S., Muller, R. U., and Ranck, J. B. Jr. (1990b). Head-direction cells recorded from the postsubiculum in freely moving rats. II. Effects of environmental manipulations. J. Neurosci. 10, 436-447.

Tseng, W., Guan, R., Disterhoft, J. F., and Weiss, C. (2004). Trace eyeblink conditioning is hippocampally dependent in mice. Hippocampus 14, 58-65.

Tsodyks, M. V., and Sejnowski, T. J. (1995). Associative memory and hippocampal place cells. Int. J. Neural. Syst. 6, 81-86.

Wallenstein, G. V., Eichenbaum, H., and Hasselmo, M. E. (1998). The hippocampus as an associator of discontiguous events. Trends Neurosci. 21,317-323.

Weiss, C., Bouwmeester, H., Power, J. M., and Disterhoft, J. F. (1999). Hippocampal lesions prevent trace eyeblink conditioning in the freely moving rat. Behav. Brain Res. 99, 123-132.

Wilson, M. A., and McNaughton, B. L. (1994). Reactivation of hippocampal ensemble memories during sleep. Science 265 676-679.
Winson, J. (1974). Patterns of hippocampal theta rhythm in the freely moving rat. Electroencephalogr. Clin. Neurophysiol. 36, 291-301.

Witter, M. P., and Amaral, D. G. (1991). Entorhinal cortex of the monkey: V. Projections to the dentate gyrus, hippocampus, and subicular complex. J. Comp. Neurol. 307, 437-459.

Wood, E. R., Dudchenko, P. A., Robitsek, R. J., and Eichenbaum, H. (2000). Hippocampal neurons encode information about different types of memory episodes occurring in the same location. Neuron 27, 623-633.

Yoshida, M., and Alonso, A. (2007). Cell-type specific modulation of intrinsic firing properties and subthreshold membrane oscillations by the $\mathrm{M}(\mathrm{Kv} 7)$-current in neurons of the entorhinal cortex. J. Neurophysiol. 98, 2779-2794.

Yoshida, M., Fransén, E., and Hasselmo, M. E. (2008). mGluRdependent persistent firing in entorhinal cortex layer III neurons. Eur. J. Neurosci. 28, 1116-1126

Yoshida, M., Giocomo, L. M., Boardman, I., and Hasselmo, M. E. (2011). Frequency of subthreshold oscillations at different membrane potential voltages in neurons at different anatomical positions on the dorsoventral axis in the rat medial entorhinal cortex. J. Neurosci. 31, 12683-12694

Yoshida, M., and Hasselmo, M. E. (2009a). Persistent firing supported by an intrinsic cellular mechanism in a component of the head direction system. J. Neurosci. 29, 4945-4952.

Yoshida, M., and Hasselmo, M. (2009b). Differences in persistent firing properties dependent upon anatomical location of neurons in rat medial entorhinal cortex. Soc. Neurosci. Abstr. 35, 193.19.

Young, B. J., Otto, T., Fox, G. D., and Eichenbaum, H. (1997). Memory representation within the parahippocampal region. J. Neurosci. 17, 5183-5195.

Zhang, K. (1996). Representation of spatial orientation by the intrinsic dynamics of the head-direction cell ensemble: a theory. J. Neurosci. 16, 2112-2126.

Zhang, Z., Reboreda, A., Alonso, A., Barker, P. A., and Séguéla, P. (2011). TRPC channels underlie cholinergic plateau potentials and persistent activity in 
entorhinal cortex. Hippocampus 21, 386-397.

Zilli, E. A., and Hasselmo, M. E. (2010). Coupled noisy spiking neurons as velocity-controlled oscillators in a model of grid cell spatial firing. J. Neurosci. 30, 13850-13860.

Zilli, E. A., Yoshida, M., Tahvildari, B., Giocomo, L. M., and Hasselmo, M. E. (2009). Evaluation of the oscillatory interference model of grid cell firing through analysis and measured period variance of some biological oscillators. PLoS Comput. Biol. 5:e1000573. doi: 10.1371/journal.pcbi.1000573

Conflict of Interest Statement: The authors declare that the research was conducted in the absence of any commercial or financial relationships that could be construed as a potential conflict of interest.

Received: 16 December 2011; accepted: 24 February 2012; published online: 15 March 2012.

Citation: Yoshida $M$, Knauer $B$ and Jochems A (2012) Cholinergic modulation of the CAN current may adjust neural dynamics for active memory maintenance, spatial navigation and time-compressed replay. Front. Neural Circuits 6:10. doi: 10.3389/fncir. 2012.00010

Copyright (C) 2012 Yoshida, Knauer and Jochems. This is an open-access article distributed under the terms of the Creative Commons Attribution Non Commercial License, which permits noncommercial use, distribution, and reproduction in other forums, provided the original authors and source are credited. 